\title{
The effect of partial replacement of soybean meal with fermented soybean meal on chicken performance and immune status
}

\author{
R. Chachaj, I. Sembratowicz', M. Krauze and K. Ognik \\ University of Life Sciences in Lublin, Faculty of Biology, Animal Sciences and Bioeconomy, \\ Department of Biochemistry and Toxicology, 20-950 Lublin, Poland
}

KEY WORDS: broilers, fermentation, performance, microbiome, immunity, soybean meal

Received: 3 April 2019

Revised: 24 June 2019

Accepted: 31 July 2019

${ }^{1}$ Corresponding author:

e-mail: iwona.sembratowicz@up.lublin.pl

\begin{abstract}
The aim of the study was to evaluate the effect of partial replacement of soybean meal (SM) with 3 or $6 \%$ of fermented soybean meal (FSM) on growth performance, gut microbiota, intestinal histology and immunity of chickens. In the study one-day-old male Ross 308 chickens raised to the age of 40 days were used. The experiment was carried out on 600 animals assigned to three experimental groups of 200 birds each (10 replications of 20 individuals each). In the control group (C), SM was the main source of dietary protein, whereas the chickens from FSM- $3 \%$ and FSM- $6 \%$ groups were fed diets in which SM was partially replaced with FSM at a dose of 3 and $6 \%$, respectively. It was shown that partial replacement of SM with FSM (both 3 and $6 \%$ ) improved the chicken growth performance and dressing percentage, and modulated the immune system. However, the introduction of a $6 \%$ dose of FSM was found to better improve the morphology of intestines (reflected by increased villi length and crypts depth) than a 3\% FSM dose. It also contributed to a decrease in total number of fungi and coliforms in the jejunum. Based on the obtained results, it can be concluded, that it is better to use a $6 \%$ share of FSM in chicken feed, than a $3 \%$ share.
\end{abstract}

\section{Introduction}

Restrictions on the use of antibiotic growth promoters in animal feeding have prompted scientists to look for other additives that stimulate immunity and improve health status and growth performance. Apart from probiotics and prebiotics, organic acids, herbal preparations, and fermented products can also exert such a beneficial effect (Nava et al., 2009). It is known that fermented feed enhances production of circulating immunoglobulins (Ig), and also increases intestinal immunity (Gao et al., 2009). Moreover, fermented diet affects not only humoral response (Ig contents, lysozyme activity, cytokine production) but also cell-mediated immunity (Zhang et al., 2007). A decrease in heterophils:lymphocytes ratio observed in chickens fed diets with fermented products suggests that such a diet may alleviate oxidative stress which could lead to suppression of immune response (Sugiharto and Ranjitkar, 2019). Owing to the presence of probiotic bacteria in fermented feed, their quantity in the gastrointestinal tract (GIT) is increased (Wang et al., 2012). Organic acids, their product - bacteriocins, and reduced gut $\mathrm{pH}$ create an unfavourable environment for the growth of certain enteropathogens in broilers: coliform bacteria (Missotten et al., 2013), Salmonella and Campylobacter (Heres et al., 2003; 2004). Modulation of intestinal microbiota using fermented feeds positively influences gut morphology, causing an increase in villus height and in villus height:crypt depth ratio (VH:CD) in the jejunum and ileum of chickens 
(Chiang et al., 2010). Augmentation of the intestinal absorption surface area may contribute to better absorption of nutrients and thus to improve growth performance.

Various authors (Kim et al., 2016; Seifi et al., 2017; Drażbo et al., 2018; Jazi et al., 2018) confirmed the beneficial effects of fermented soybeans, rapeseed or faba beans in poultry feed. Fermentation is an easy and inexpensive way to improve the nutritional value of soybeans, which in addition to high-value protein also contain anti-nutritional factors (ANFs). The fermentation process efficiently eliminates soybean ANFs, such as trypsin inhibitors (TI), phytate, galactooligosaccharides and lectins (Hong et al., 2004; Jazi et al., 2018), as well as allergenic proteins (Seo and Cho, 2016).

Fermented soybean meal (FSM) is richer in small peptides, fats, minerals and vitamins than non-fermented soybean meal (SM). A very important effect of soybean fermentation is the degradation of non-starch polysaccharides that are not digested by chickens. In general, the changes that take place during fermentation of soybeans lead to the increase in the amount of nutrients, minerals and vitamins that are more easily absorbed and utilized, and so improve chicken health and assure better growth performance (Sugiharto and Ranjitkar, 2019). What is more, due to the reduced contents of TI and other ANFs, the activity of digestive enzymes increases (Feng et al., 2007).

In the literature data concerning FSM as a component of poultry feed, the proportion of FSM has ranged from 0.5 to 3\% (Mathivanan et al., 2006; Kim et al., 2016), or SM has been completely replaced by FSM (Feng et al., 2007). Despite the strong arguments for using FSM in chicken diets (improvement in growth performance parameters, intestinal histology and gut microbiota), the appropriate dosage has not been fully researched and established. It should be also remembered that alongside the benefits, fermented raw materials also contain compounds that may reduce the palatability of feed (acetic acid) and adversely affect metabolic reactions (biogenic amines generated during fermentation e.g., cadaverine, putrescine and histamine) (Canibe and Jensen, 2012). In addition, fermentation may also degrade certain nutrients, such as free lysine (Canibe and Jensen, 2003).

Therefore, the aim of the study was to determine whether replacing raw SM with FSM at a dose of 3 and $6 \%$ would positively affect the growth, gut microbiota, intestinal histology and immunity of chickens.

\section{Material and methods}

\section{Fermented protein products}

Fermented soybean meal (FSM) from European Protein AS (Bække, Denmark) was used in the study. FSM was prepared from soy by-products, i.e. solvent-extracted soybean meal (SM, containing $471 \mathrm{~g} / \mathrm{kg}$ crude protein (CP)), that were fermented and then dried, with added potatoes and selected lactic acid bacteria. The compositions of the SM and FSM are presented in Table 1. The food source for Lactobacillus bacteria consisted of potato starch, potatoes and wheat.

Table 1. Composition of non-fermented (SM) and fermented (FSM) soybean meal

\begin{tabular}{lcc}
\hline Indices & SM & FSM \\
\hline Ingredients g/kg & & \\
$\quad$ dry matter & 897 & 895 \\
crude protein & 471 & 505 \\
crude fat & 20 & 22 \\
crude fibre & 36 & 34 \\
crude ash & 65 & 64 \\
non-starch polysaccharides (NSP) & 124 & 114 \\
lactic acid & 2 & 74 \\
lysine & 24.6 & 27.9 \\
methionine & 5.8 & 6.9 \\
threonine & 17.4 & 19.8 \\
tryptophan & 6.2 & 6.4 \\
Lactobacillus, log CFU/g & 4.2 & 6.86 \\
Trypsin inhibitors (TI) & 2.9 & $<0.5$ \\
$\beta$-conglycinin & 58.9 & $<2$ \\
Raffinose & 45 & $<5$ \\
\hline
\end{tabular}

\section{Animals and diets}

The experimental procedure was approved by the Second Local Ethics Committee for Experiments with Animals in Lublin (approval no. 30/2016).

In the study one-day-old male Ross 308 chickens raised in pens on litter until the age of 40 days in a building with a controlled environment and free access to feed and water were used. The experiment was carried out on 600 animals assigned to three experimental groups of 200 birds each (10 replications of 20 individuals each). During each of three feeding phases, the birds were fed isonitrogenous and isocaloric diets in pellet form ad libitum. In the control group (C), SM was the main source of dietary protein, whereas the remaining groups were fed diets in which SM was partially replaced with FSM at a dose of 3 and $6 \%$ (FSM-3\% and FSM-6\%, respectively).

The diets were prepared by Trouw Nutrition (Grodzisk Mazowiecki, Poland). The nutritional 
Table 2. Composition and nutritional value of feeds ${ }^{1}$

\begin{tabular}{|c|c|c|c|c|c|c|c|c|c|}
\hline \multirow{2}{*}{ Indices } & \multicolumn{3}{|c|}{ days $1-14$} & \multicolumn{3}{|c|}{ days $15-32$} & \multicolumn{3}{|c|}{ days $33-40$} \\
\hline & $\mathrm{C}$ & FSM-3\% & FSM-6\% & $\mathrm{C}$ & FSM-3\% & FSM- $6 \%$ & $\mathrm{C}$ & FSM-3\% & FSM-6\% \\
\hline \multicolumn{10}{|l|}{ Ingredient, \% } \\
\hline wheat & 38.58 & 38.47 & 38.37 & 41.79 & 41.68 & 41.57 & 47.35 & 47.23 & 47.14 \\
\hline maize & 20.00 & 20.00 & 20.00 & 20.00 & 20.00 & 20.00 & 20.00 & 20.00 & 20.00 \\
\hline soybean & 33.46 & 30.56 & 27.65 & 29.52 & 26.61 & 23.71 & 23.79 & 20.89 & 17.98 \\
\hline fermented soybean & - & 3.00 & 6.00 & - & 3.00 & 6.00 & - & 3.00 & 6.00 \\
\hline soybean oil & 3.83 & 3.84 & 3.85 & 4.88 & 4.90 & 4.91 & 5.55 & 5.56 & 5.57 \\
\hline $\mathrm{NaCl}$ & 0.33 & 0.33 & 0.33 & 0.33 & 0.33 & 0.33 & 0.33 & 0.34 & 0.33 \\
\hline chalk & 1.26 & 1.26 & 1.26 & 1.14 & 1.14 & 1.14 & 0.96 & 0.96 & 0.96 \\
\hline monocalcium phosphate & 1.31 & 1.31 & 1.31 & 1.23 & 1.23 & 1.23 & 0.98 & 0.98 & 0.98 \\
\hline methionine & 0.29 & 0.29 & 0.29 & 0.26 & 0.26 & 0.26 & 0.21 & 0.21 & 0.21 \\
\hline L-lysine & 0.34 & 0.34 & 0.34 & 0.27 & 0.27 & 0.27 & 0.25 & 0.25 & 0.25 \\
\hline L-threonine & 0.10 & 0.10 & 0.10 & 0.08 & 0.08 & 0.08 & 0.08 & 0.08 & 0.08 \\
\hline vitamin-mineral premix ${ }^{2}$ & 0.50 & 0.50 & 0.50 & 0.50 & 0.50 & 0.50 & 0.50 & 0.50 & 0.50 \\
\hline \multicolumn{10}{|l|}{ Calculated nutrient content } \\
\hline $\mathrm{ME}, \mathrm{kcal} / \mathrm{kg}$ & 2950 & 2950 & 2950 & 3050 & 3050 & 3050 & 3150 & 3150 & 3150 \\
\hline ME, MJ & 12.91 & 12.91 & 12.91 & 13.32 & 13.32 & 13.32 & 13.74 & 13.74 & 13.74 \\
\hline crude protein, $\%$ & 22.00 & 22.00 & 22.00 & 20.50 & 20.50 & 20.50 & 18.50 & 18.50 & 18.50 \\
\hline lysine, \% & 1.35 & 1.35 & 1.35 & 1.20 & 1.20 & 1.20 & 1.05 & 1.05 & 1.05 \\
\hline Met + Cys, \% & 0.98 & 0.98 & 0.98 & 0.92 & 0.92 & 0.92 & 0.82 & 0.82 & 0.82 \\
\hline threonine, $\%$ & 0.88 & 0.88 & 0.88 & 0.80 & 0.80 & 0.80 & 0.72 & 0.72 & 0.72 \\
\hline $\mathrm{Ca}, \%$ & 0.95 & 0.95 & 0.95 & 0.88 & 0.88 & 0.88 & 0.75 & 0.75 & 0.75 \\
\hline available $\mathrm{P}, \%$ & 0.45 & 0.45 & 0.45 & 0.43 & 0.43 & 0.43 & 0.37 & 0.37 & 0.37 \\
\hline $\mathrm{Na}, \%$ & 0.15 & 0.15 & 0.15 & 0.15 & 0.15 & 0.15 & 0.15 & 0.15 & 0.15 \\
\hline
\end{tabular}

${ }^{1}$ feeds: C - control, FSM-3\% - feed replaced with $3 \mathrm{~g}$ of FSM per kg diet, FSM-6\% - feed replaced with $6 \mathrm{~g}$ of FSM per $\mathrm{kg}$ diet; ${ }^{2}$ contained per kg of diet: IU: vit. A 15000 , vit. $D_{3} 5000$, vit. E 100; mg: vit. $K_{3} 4$, vit. $B_{1} 5$, vit. $B_{2} 15$, vit. $B_{6} 6$, vit. $B_{12} 0.04$, nicotinic acid 100 , calcium pantothenicum 32.7, folic acid 4, choline 700, biotin 0.35, Se 0.3, Fe 60, I 1.5, Ca 1.04, Mn 100, Zn 80, Cu 8; ME - metabolizable energy; Met + Cys - methionine and cysteine

value of the diets was in accordance with the nutrient requirements of chickens. Their composition was established in accordance with Smulikowska and Rutkowski (2005). The composition of the control and experimental diets prepared in each feeding period is presented in Table 2 .

\section{Growth trial and sample collection}

At the end of each period, the body weight, feed intake and mortality rates of chickens were recorded, with each pen of 20 birds considered an experimental unit. Feed conversion ratio (FCR) was calculated for each group. At the end of the experiment, at 40 day of age, nine birds representing the average BW per treatment were selected, tagged and fasted for $8 \mathrm{~h}$. Blood samples were collected from the wing vein intravitally, and birds were sacrificed by cervical dislocation. After slaughter cloacal samples were individually collected using sterile swabs. Samples from the broiler carcasses were collected after plucking, evisceration, washing and chilling. One set of swabs was placed into
Cary Blair transport medium (Oxoid, Hampshire, UK) for the isolation of Campylobacter spp. and the other set was placed into individual Buffered Peptone Water (Oxoid, Hampshire, UK) for the isolation of Salmonella spp. Then samples were transported to the laboratory under cool condition. During dissection of the chickens, samples of the digesta were collected from the jejunum into sterile containers for microbiological analysis. To study intestinal histology, samples (section $2 \mathrm{~cm}$ long, cut $1 \mathrm{~cm}$ behind Meckel's diverticulum) were taken from the jejunum and placed in $4 \%$ buffered formaldehyde (Sigma-Aldrich, Poznań, Poland) for 5 days and then stored in $70 \%$ ethanol.

\section{Microbiological analysis}

The total number of mesophilic aerobic bacteria in the digesta was determined on nutrient agar, incubated for $48 \mathrm{~h}$ at $37^{\circ} \mathrm{C}$, the total number of yeast and moulds on DG18 agar, incubated for 5-7 days at $25{ }^{\circ} \mathrm{C}$, the total number of coliform bacteria on VRBL agar, incubated for $24 \mathrm{~h}$ at $37{ }^{\circ} \mathrm{C}$, and the 
number of Escherichia coli on $\mathrm{mFC}$ agar, incubated for $18-24 \mathrm{~h}$ at $44{ }^{\circ} \mathrm{C}$. Following incubation the colonies were counted and the number was converted to colony-forming unit (CFU)/g. For identification of microorganisms the colonies were evaluated macro- and microscopically and Gram staining was performed. Final identification was carried out using API tests (BioMérieux, Warsaw, Poland). All tests were performed according to Polish standards: PN-ISO 4832 and PN-EN ISO 7218.

The isolation and identification of Salmonella spp. from cloaca and carcass was done according to ISO method 6579:2002. Peptone water (Oxoid, Hampshire, UK) was used as primary enrichment media (incubation at $37^{\circ} \mathrm{C}$ for $24 \mathrm{~h}$ under aerobic condition). Then, $1 \mathrm{ml}$ of culture was transferred into $10 \mathrm{ml}$ of Rappaport Vassidalis broth (RV) (Oxoid, Hampshire, UK) and was incubated at $42{ }^{\circ} \mathrm{C}$ for $24 \mathrm{~h}$. One loop-full of the colony from broth was streaked on Xylose-Lysine-Tergitol (XLD 4, Merck, Warsaw, Poland) agar and incubated at $37{ }^{\circ} \mathrm{C}$ for $24 \mathrm{~h}$. Then the positive samples were inoculated on SS agar and incubated at $37^{\circ} \mathrm{C}$ for $24 \mathrm{~h}$. As Salmonella positive the colony with a black center in XLD and blackish growth in SS agar were considered.

For isolation and identification of Campylobacter spp. selective agar base (Modified CCDA Preston, Oxoid, Hampshire, UK) with CCDA selective supplement (Oxoid, Hampshire, UK) was used. The plates were incubated $48 \mathrm{~h}$ at $42{ }^{\circ} \mathrm{C}$, under microaerophilic condition (5\% oxygen, $10 \%$ carbon dioxide and $85 \%$ nitrogen) in an anaerobic jar. Each typical colony of Campylobacter was evaluated for morphology (Gram-staining) and motility ('hanging drop' technique). The presumptive colonies of Campylobacter spp. were subcultured on Columbia Blood agar (Oxoid, Hampshire, UK) with $5 \%$ defibrinated horse blood, and incubated at $42{ }^{\circ} \mathrm{C}$ for $48 \mathrm{~h}$ to obtain pure culture.

\section{Histo-morphometric analysis}

Once fixed tissue fragments were passed through increasing concentrations of alcohol solutions (70\%, 95\%, absolute) for dehydratation, cleared using xylene as clearing agent and embedded into paraffin blocks in a tissue processor (Leica TP-20, Leica Microsystems, Wetzlar, Germany). All tissue processing was done according to Ibrahim et al. (2018). Morphometric evaluation of the villi length and crypt depth was carried out using a computerassisted microscopic image analysis system. The system includes a light microscope (Nikon Eclipse E600, Tokyo, Japan) with a digital camera
(Nikon DS-Fi1, Tokyo, Japan) and a PC with image-analysis software (NIS-Elements BR-2.20, Laboratory Imaging, Nikon, Tokyo, Japan). In each jejunum tissue slide, 20 villi cut in two lengthwise and 20 crypts were measured. The length of the villi was measured from the tip to the base.

\section{Blood analysis}

Serum lysozyme content was determined by the turbidimetric method (Siwicki and Anderson, 1993). Ceruloplasmin (Cp) activity in the blood plasma was determined by the $p$-phenylenediamine colorimetric method according to Sunderman and Nomoto (1970). Class A, M and Y immunoglobulins (IgA, $\operatorname{IgM}$ and $\operatorname{IgY}$, respectively) and interleukin-6 (IL-6) in the blood were determined in an ELISA reader (Sunrise ${ }^{\mathrm{TM}}$ Absorbance Reader, Tekan, Männedorf, Switzerland) using assays from Elabscience Biotechnology Co., Ltd (Houston, TX, USA).

\section{Statistical analysis}

Data were processed by one-way analysis of variance (ANOVA) and the results were presented as mean values with pooled standard error (SEM) (Statistica software package version 13.1 (2016), StatSoft Polska, Krakow, Poland). Differences among means were compared using Duncan's multiple-range test. Treatment effects were considered to be significant at $P \leq 0.05$.

\section{Results}

\section{Performance and slaughter analysis}

Statistical analysis of the obtained data revealed no difference in body weight between 14-day broiler chickens from different treatments (Table 3). Diet replaced with $6 \%$ FSM improved $(P \geq 0.05)$ broiler chicken body weight at days 32 and 40 of age ( $P=0.035$ and $P=0.021$, respectively). In comparison to FSM-3\%, chickens from FSM-6\% group had also higher FCR $(P=0.041)$. The carcass yield was higher in the groups of chickens receiving feed replaced with 3 and $6 \%$ of FSM than in the $\mathrm{C}$ group $(P=0.044)$. In FSM-3\% chickens higher proportions of breast muscles, thigh muscles, shank muscles and shinbone than in the $\mathrm{C}$ group $(P=0.026, P=0.012$, $P=0.022$ and $P=0.016$, respectively) were observed. Chickens receiving feed with a $6 \%$ share of FSM had lower liver weight and thighbone weight than those from the $\mathrm{C}$ group $(P=0.034$ and $P=0.025$, respectively; Table 4). Significant differences in carcass characteristics were observed between FSM-3\% and 
Table 3. Growth performance of chickens receiving diets containing non-fermented (SM) and fermented (FSM) soybean meal

\begin{tabular}{lccclll}
\hline Indices & \multicolumn{2}{l}{ Treatment $^{1}$} & \multirow{2}{*}{ SEM } & P-value \\
\cline { 2 - 5 } & $\mathrm{C}$ & FSM-3\% & FSM-6\% & & \\
\hline Body weight, $\mathrm{g}$ & & & & & \\
$\quad$ day 1 & 42 & 42 & 42 & 0.0001 & 0.879 \\
day 14 & 388 & 402 & 415 & 0.007 & 0.281 \\
day 32 & $1505^{\mathrm{b}}$ & $1536^{\mathrm{ab}}$ & $1567^{\mathrm{a}}$ & 0.09 & 0.035 \\
day 40 & $2106^{\mathrm{b}}$ & $2129^{\mathrm{ab}}$ & $2136^{\mathrm{a}}$ & 0.015 & 0.021 \\
DFI, g/bird/day & 0.086 & 0.085 & 0.089 & 0.004 & 0.347 \\
FCR, g/g & $1.682^{\mathrm{ab}}$ & $1.630^{\mathrm{b}}$ & $1.700^{\mathrm{a}}$ & 0.012 & 0.041 \\
Liveability, \% & 98.5 & 98.0 & 99.5 & - & - \\
\hline
\end{tabular}

${ }^{1}$ treatment: C - control, FSM- $3 \%$ - feed replaced with $3 \mathrm{~g}$ of FSM per $\mathrm{kg}$ diet, FSM-6\% - feed replaced with $6 \mathrm{~g}$ of FSM per $\mathrm{kg}$ diet; ab - means with different superscripts within a row are significantly different at $P \leq 0.05$; SEM - standard error of mean; DFI - daily feed intake; FCR - feed conversion ratio

Table 4. Results of slaughter analysis of chickens receiving diets containing non-fermented (SM) and fermented (FSM) soybean meal $($ body weight $=100 \%)$

\begin{tabular}{llclll}
\hline \multirow{2}{*}{ Indices, \% } & \multicolumn{2}{l}{ Treatment $^{1}$} & \multirow{2}{*}{ SEM } & \multirow{2}{*}{ P-value } \\
\cline { 2 - 5 } & $\mathrm{C}$ & FSM-3\% & FSM-6\% & & \\
\hline Carcass yield & $74.78^{\mathrm{b}}$ & $81.10^{\mathrm{a}}$ & $83.90^{\mathrm{a}}$ & 0.106 & 0.044 \\
Breast muscles & $25.82^{\mathrm{b}}$ & $27.07^{\mathrm{a}}$ & $26.37^{\mathrm{ab}}$ & 0.009 & 0.026 \\
Thigh muscles & $10.04^{\mathrm{b}}$ & $10.51^{\mathrm{a}}$ & $9.86^{\mathrm{b}}$ & 0.022 & 0.012 \\
Drumstick muscles & $7.39^{\mathrm{b}}$ & $8.18^{\mathrm{a}}$ & $7.30^{\mathrm{b}}$ & 0.034 & 0.022 \\
Liver & $2.82^{\mathrm{a}}$ & $2.59^{\mathrm{c}}$ & $2.67^{\mathrm{b}}$ & 0.003 & 0.034 \\
Gizzard & 1.43 & 1.40 & 1.42 & 0.128 & 0.689 \\
Heart & 0.47 & 0.48 & 0.45 & 0.073 & 0.062 \\
Abdominal fat & 0.48 & 0.49 & 0.42 & 0.111 & 0.069 \\
Thighbone & $1.06^{\mathrm{a}}$ & $0.97^{\mathrm{b}}$ & $0.72^{\mathrm{c}}$ & 0.063 & 0.025 \\
Shinbone & $1.81^{\mathrm{a}}$ & $1.74^{\mathrm{b}}$ & $1.81^{\mathrm{a}}$ & 0.041 & 0.016
\end{tabular}

1 treatment: C - control, FSM-3\% - feed replaced with $3 \mathrm{~g}$ of FSM per kg diet, FSM-6\% - feed replaced with $6 \mathrm{~g}$ of FSM per kg diet; ab - means with different superscripts within a row are significantly different at $P \leq 0.05$; SEM - standard error of mean

FSM-6\% groups. In relation to chickens receiving diet with 3\% share of FSM, chickens receiving diet with $6 \%$ of FSM had higher proportions of thigh muscles, shank muscles and thighbone while lower proportion of liver and shinbone.

\section{Microbiology of the gut}

It was observed that FSM-3\% and FSM-6\% diets reduced the total microbial count and total fungal count in the contents of the small intestine $(P<0.001$, both $)$ in comparison to the $\mathrm{C}$ group. In chickens from FSM- $6 \%$ total number of fungi was significantly lower as compared to FSM-3\% group. In addition, in chickens from FSM- $6 \%$ group fewer coliforms $(P<0.001)$ in the contents of the small intestine were noted than in the $\mathrm{C}$ group.
Table 5. Microbiological and histo-morhological analysis of the jejunum of the chickens receiving diets containing non-fermented (SM) and fermented (FSM) soybean meal

\begin{tabular}{|c|c|c|c|c|c|}
\hline \multirow{2}{*}{ Indices } & \multicolumn{3}{|c|}{ Treatment $^{1}$} & \multirow{2}{*}{ SEM } & \multirow{2}{*}{ P-value } \\
\hline & $C$ & FSM-3\% & FSM- $6 \%$ & & \\
\hline $\begin{array}{l}\text { Total number of fungi, } \\
\text { CFU/g }\end{array}$ & $45^{a}$ & $23^{b}$ & $14^{c}$ & 0.356 & $<0.001$ \\
\hline $\begin{array}{l}\text { Total number of mi- } \\
\text { croorganisms, CFU/g }\end{array}$ & $184545^{a}$ & $19091^{b}$ & $19545^{b}$ & 1.967 & $<0.001$ \\
\hline $\begin{array}{l}\text { Total number of } \\
\text { coliforms, CFU/g }\end{array}$ & $3636^{a}$ & $3182^{a}$ & $909^{b}$ & 0.987 & $<0.001$ \\
\hline $\begin{array}{l}\text { Mean villi length, } \mu \mathrm{m} \\
\text { Mean crypt depth, } \mu \mathrm{m}\end{array}$ & $\begin{array}{r}1499.5^{b} \\
188.5^{b}\end{array}$ & $\begin{array}{r}1485.9^{b} \\
186.8^{b}\end{array}$ & $\begin{array}{r}1771.6^{a} \\
212.9^{a}\end{array}$ & $\begin{array}{l}0.158 \\
0.083\end{array}$ & $\begin{array}{l}0.013 \\
0.042\end{array}$ \\
\hline $\begin{array}{l}\text { Villus height:crypt } \\
\text { depth ratio }\end{array}$ & 7.95 & 7.95 & 8.32 & 0.025 & 0.51 \\
\hline
\end{tabular}

1 treatment: C - control, FSM-3\% - feed replaced with $3 \mathrm{~g}$ of FSM per $\mathrm{kg}$ diet, FSM-6\% - feed replaced with $6 \mathrm{~g}$ of FSM per kg diet; ab - means with different superscripts within a row are significantly different at $P \leq 0.05$; SEM - standard error of mean

In the cloacal swabs and swabs of the carcass from all groups, the presence of Salmonella spp. and Campylobacter spp. was not detected (Table 5).

\section{Histology of the gut}

Longer villi length $(P=0.013)$ and greater crypt depth $(P=0.042)$ were noted in the small intestine of chickens from FSM-6\% than in the $\mathrm{C}$ group (Table 5). There were no significant differences between the groups in the VH:CD ratio.

\section{Immune parameters of blood}

In comparison to chickens from the $\mathrm{C}$ group, the plasma lysozyme levels were higher in FSM-3\% and FSM-6\% chickens $(P=0.017)$, and the levels of IgM and IgY were lower $(P=0.012$ and $P<0.001$, respectively; Table 6). There were no differences among the groups in IL- 6 content and Cp activity.

Table 6. Blood immunological indices in chickens receiving diets containing non-fermented (SM) and fermented (FSM) soybean meal

\begin{tabular}{|c|c|c|c|c|c|}
\hline \multirow{2}{*}{ Indices } & \multicolumn{3}{|c|}{ Treatment $^{1}$} & \multirow{2}{*}{ SEM } & \multirow{2}{*}{$P$-value } \\
\hline & $\mathrm{C}$ & FSM-3 & 6 FSM- $6 \%$ & & \\
\hline -ysozyme, mg/l & $3.084^{b}$ & $3.747^{\mathrm{a}}$ & $3.644^{\mathrm{a}}$ & 0.135 & 0.017 \\
\hline mmunoglobulin A, ng/ml & 3.313 & 3.304 & 3.357 & 0.055 & 0.138 \\
\hline Immunoglobulin $\mathrm{M}, \mathrm{ng} / \mathrm{ml}$ & $0.096^{a}$ & $0.071^{c}$ & $0.082^{b}$ & 0.023 & 0.012 \\
\hline Immunoglobulin Y, ng/ml & $0.132^{\mathrm{a}}$ & $0.120^{b}$ & $0.102^{c}$ & 0.036 & $<0.001$ \\
\hline Ceruloplasmin, U/I & 0.027 & 0.028 & 0.029 & 0.077 & 0.447 \\
\hline nterleukin 6, pg/ml & 0.172 & 0.174 & 0.170 & 0.126 & 0.256 \\
\hline
\end{tabular}

1 treatment: C - control, FSM-3\% - feed replaced with $3 \mathrm{~g}$ of FSM per $\mathrm{kg}$ diet, FSM-6\% - feed replaced with $6 \mathrm{~g}$ of FSM per $\mathrm{kg}$ diet; ab - means with different superscripts within a column are significantly different at $P \leq 0.05$; SEM - standard error of mean 


\section{Discussion}

In fermentation various starter microorganisms are involved, and hence this process may generate different final products. For example, lactic acid bacteria (LAB) produce lactic acid and citric acid, whereas yeast - ethanol and carbon dioxide. The results of the analysis of SM before fermentation and after bacterial fermentation using a Lactobacillus strain confirm the general rule that this process usually leads to an increase in the level of organic acids and in the population of LAB in the product (Sugiharto and Rajnitkar, 2019). These properties, together with a reduced number of Enterobacteriacea bacteria in fermented products, are very beneficial for the chicken health and GIT functioning. The contents of TI and the allergenic protein $\beta$-conglycinin, which was considerably reduced in FSM as compared to SM, are also significant. This effect of fermentation was observed by other authors (Li et al., 2014; Jazi et al., 2018). According to Hong et al. (2004), ANFs are significantly reduced during fermentation, while the content of small, easily digestible peptides increases. The results of research by Amadou et al. (2010) have shown that soybean fermentation by LAB such as Lactobacillus plantarum contributes to protein hydrolysis and increases the release of free amino acids, thus increasing their total quantity in the product. The contents of some amino acids e.g., histidine, threonine, methionine and phenylalanine, do not change after fermentation, while the contents of leucine, isoleucine, aspartic acid and proline increase. We have shown that FSM contained slightly higher amounts of lysine, threonine and tryptophan than SM, as well as more crude protein, which was also indicated in the studies by Hong et al. (2004) and Teng et al. (2012). The changes observed as a result of the fermentation of SM also included a reduction in non-starch polysaccharides (NSP) and raffinose. These sugars are not digested in the GIT of birds due to the lack of endogenous intestinal enzymes. The presence of soluble NSPs increases the viscosity of the digestive tract, thereby restricting the access of digestive enzymes to nutrients and reducing their intestinal absorption. Degradation of NSP during fermentation is the main factor increasing broiler performance (Sugiharto and Ranjitkar, 2019).

According to Missotten et al. (2013) fermented feed decreased the feed intake of broilers during starter and grower phases, leading to growth retardation. It was probably a consequence of worse palatability, or less contents of essential nutrients (e.g., lysine). In the present study, the replacement of SM by FSM did not affect feed intake, but it contributed to an increase in chickens body weight. Birds receiving feed replaced with $6 \%$ of FSM attained a significantly higher final body weight than birds from the $\mathrm{C}$ group. Kim et al. (2016) reported that the use of a 3\% share of BacillusFSM increased weight gains. Feng et al. (2007), in an experiment in which SM was completely replaced by FSM, noted an increase in body weight gain with higher feed intake. The ability of FSM to improve weight gains has also been shown in experiments on piglets. According to the researchers, the main factor determining this effect is the improvement in the nutritional value and digestibility of feed components (Canibe and Jensen, 2012; Yuan et al., 2017). Feng et al. (2007) have shown that the introduction of FSM into the diet of chickens contributes to a significant increase in the activity of digestive enzymes (trypsin, lipase and protease) in the intestinal lumen.

According to some authors, despite the favourable modification of the microbiota and histology of the intestine and the improvement in growth parameters, the use of fermented components in chicken diets has little effect on the slaughter value of the carcass (Mathivanan et al., 2006; Kayode et al., 2012). Some researchers point out only differences in fat content, which either increased or decreased (Nie et al., 2015). A reduction of fat in the carcass is explained by the increase in $\beta$-oxidation of fatty acids and by the hydrolysis of triacylglycerols.

We have shown that the introduction of FSM, in the amount of both 3 and $6 \%$, positively affected the dressing percentage. In birds receiving feed replaced with $3 \%$ of FSM the yield of breast muscles and leg muscles was improved as well. Moreover, there was a reduction in the percentage share of liver in the carcass (for both FSM-3\% and FSM-6\% groups), which may have been linked to decreased exposure to xenobiotic substances (e.g., mould toxins) that are metabolized in this organ. One of the known benefits of fermentation is the reduction in undesirable substances in the product, such as ANFs, allergens and mycotoxins (Sugiharto and Ranjitkar, 2019). The presence of ANFs and allergenic factors in feed may adversely affect the histomorphology of the intestine, as they induce inflammatory reactions within the intestinal mucosa that may result in atrophy of the intestinal villi. According to Chiang et al. (2010) improvement in the intestinal morphology of chickens receiving fermented feed is associated with the smaller amount of toxins and allergens (glycinin and $\beta$-conglycinin) in it, as compared to standard feed. The beneficial effects of FSM on gut morphology may also be due to the larger number of short peptides relative to those contained in SM (Feng et al., 2007).

The improvement in growth rates observed when a $6 \%$ share of FSM was introduced into the 
feed may therefore be the result of its beneficial effect on the intestinal morphology. The intestinal mucosa plays an essential role in the digestion and absorption of dietary nutrients. The feeding with fermented materials has been reported to improve intestinal morphology of chickens leading to an increase of villus height and VH:CD ratio (Mathivanan et al., 2006; Chiang et al., 2010; Missotten et al., 2013). An increase in the $\mathrm{VH}: \mathrm{CD}$ ratio is treated as an indicator of absorptive capability of the small intestine (Missotten et al., 2013). The results of the present study indicate that replacing SM with FSM contributed to an increase in villi length within the jejunum, which was accompanied by an increase in crypt depth. Therefore, the $\mathrm{VH}: \mathrm{CD}$ ratio did not increase in comparison to untreated birds. Deeper crypts ensure the villi renewal in response to epithelial exfoliation or inflammatory reactions induced by the presence of pathogens or toxins (Awad et al., 2010).

Another important factor maintaining the proper condition of the intestinal mucosa is an appropriate composition of intestinal flora, especially an increase in the population of probiotic bacteria of the genus Lactobacillus (LAB), which produce lactic acid and other organic acids (Chiang et al., 2010). The use of fermented components in chicken feed leads to an increase in the LAB population in the gut, thereby reducing the $\mathrm{pH}$ in the GIT (Savvidou et al., 2009; Sun et al., 2013). Increased acidity in the intestinal contents and the presence of substances inhibiting the development of pathogenic microbes produced by probiotic bacteria, such as hydrogen peroxide or bacteriocins, contribute to inhibition of the development of enteropathogens, including coliform bacteria and fungi. It is worth noting that in the intestine of chickens receiving FSM- $6 \%$ treatment, the number of coliform bacteria decreased substantially, and the fungal count and total microbial count decreased as well. These changes were also observed when FSM$3 \%$ feed was used (although the number of coliforms did not decrease). Reducing the bacterial count in the GIT is beneficial, as it reduces competition for easily available nutrients, which leads to improved performance in broilers (Engberg et al., 2009). Scientific research also indicates a reduction in the number of Escherichia coli bacteria in broiler chickens receiving fermented feeds (Sugiharto and Ranjitkar, 2019). Other authors have shown an inhibitory effect of this type of chicken diet on the Salmonella and Campylobacter populations (Heres et al., 2003; 2004).

Changes in the microbiological composition of the intestine resulting from the introduction of fermented components into feeds, specifically the increase in the probiotic LAB population, may have a positive effect on the chicken immune responses (Missotten et al., 2013). The effects of fermented diet components on cellular and humoral immune mechanisms of chickens have been shown in studies by other authors (Gao et al., 2009). LAB, by promoting the production of various types of cytokines (interleukins, tumour necrosis factor - TNF $\alpha$ ), can stimulate the production of antibodies and modify immune response (Kabir, 2009). The increased number of small peptides in fermented ingredients also favours the formation of immunoglobulins (Teng et al., 2012). Feng et al. (2007) have shown that broilers receiving FSM in their feed instead of SM had higher serum levels of IgA and IgM, while the IgY level remained unchanged. The results of our research indicate that the partial replacement of SM with FSM (3 and 6\%) led to a reduction in circulating immunoglobulins (except $\operatorname{IgA}$ ), which in the light of the above information is difficult to explain. Some researchers, however, point out that a diet containing fermented ingredients may lead to a reduction in oxidative stress and may induce suppression of some immune parameters (interferon: INF ; interleukins: IL-4, IL-13, IL-18) (Sugiharto and Ranjitkar, 2019). The results of our study revealed that feed with FSM had no effect on pro-inflammatory IL-6 contents and Cp (acute-phase protein) activity in blood. Choi et al. (2014) administered fermented seaweed to chickens observed an elevation in serum IgM and IgA contents but a decrease in IgY concentration. So, the effects of diets with fermented components on immune response may be different. It is worth noting, that while FSM was found to have an inhibitory effect on the level of immunoglobulins in the blood, it caused a significant increase in the content of lysozyme, an important component of non-specific immunity. A decrease in the number of enteropathogens and reduced content of ANFs and allergenic factors in feed are known to minimize inflammatory reactions in the intestine, which may result in modulation (extinction) of some immune responses in the host.

\section{Conclusions}

Replacement of non-fermented soybean meal (SM) with fermented soybean meal (FSM) at the amount of 3 or $6 \%$ in the feed improved the chicken growth performance and the dressing percentage and modulated immune system. However, the replacement of a $6 \%$ dose of FSM was found to be more favourable than replacement of a 3\% FSM dose because it also improved the morphology and microbiota of the intestines. 


\section{Acknowledgements}

This research was partially supported by FeedStar Ltd. (Grodzisk Mazowiecki, Poland) and European Protein AS (Bække, Denmark). The work was financed by statutory funds ZKT/DS3.

\section{References}

Amadou I., Amza T., Foh M.B.K., Kamara M.T., Le G.-W., 2010. Influence of Lactobacillus plantarum Lp6 fermentation on the functional properties of soybean protein meal. Emir. J. Food Agric. 22, 456-465, https://doi.org/10.9755/ejfa.v22i6.4663

Awad W.A., Ghareeb K., Böhm J., 2010. Effect of addition of a probiotic micro-organism to broiler diet on intestinal mucosal architecture and electrophysiological parameters. J. Anim. Physiol. Anim. Nutr. 94, 486-494, https://doi.org/10.1111/ j.1439-0396.2009.00933.x

Canibe N., Jensen B.B., 2003. Fermented and nonfermented liquid feed to growing pigs: Effect on aspects of gastrointestinal ecology and growth performance. J. Anim. Sci. 81, 2019-2031, https://doi.org/10.2527/2003.8182019x

Canibe N., Jensen B.B., 2012. Fermented liquid feed - microbial and nutritional aspects and impact on enteric diseases in pigs. Anim. Feed Sci. Technol. 173, 17-40, https://doi. org/10.1016/j.anifeedsci.2011.12.021

Chiang G., Lu W.Q., Piao X.S., Hu J.K., Gong L.M., Thacker P.A., 2010. Effects of feeding solid-state fermented rapeseed meal on performance, nutrient digestibility, intestinal ecology and intestinal morphology of broiler chickens. AsianAustralas. J. Anim. Sci. 23, 263-271, https://doi.org/10.5713/ ajas.2010.90145

Choi Y.J., Lee S.R., Oh J.-W., 2014. Effects of dietary fermented seaweed and seaweed fusiforme on growth performance, carcass parameters and immunoglobulin concentration in broiler chicks. Asian-Australas. J. Anim. Sci. 27, 862-870, https://doi. org/10.5713/ajas.2014.14015

Drażbo A., Mikulski D., Jankowski J., Zduńczyk Z., 2018. The effect of diets containing raw and fermented faba beans on gut functioning and growth performance in young turkeys. J. Anim. Feed Sci. 27, 65-73, https://doi.org/10.22358/jafs/82779/2018

Engberg R.M., Hammershøj M., Johansen N.F., Abousekken M.S., Steenfeldt S., Jensen B.B., 2009. Fermented feed for laying hens: effects on egg production, egg quality, plumage condition and composition and activity of the intestinal microflora. Br. Poult. Sci. 50, 228-239, https://doi. org/10.1080/00071660902736722

Feng J., Liu X., Xu Z.R., Liu Y.Y., Lu Y.P., 2007. Effects of Aspergillus oryzae 3.042 fermented soybean meal on growth performance and plasma biochemical parameters in broilers. Anim. Feed Sci. Technol. 134, 235-242, https://doi.org/10.1016/j. anifeedsci.2006.08.018

Gao J., Zhang H.J., Wu S.G., Yu S.H., Yoon I., Moore D., Gao Y.P., Yan H.J., Qi G.H., 2009. Effect of Saccharomyces cerevisiae fermentation product on immune functions of broilers challenged with Eimeria tenella. Poult. Sci. 88, 2141-2151, https://doi.org/10.3382/ps.2009-00151

Heres L., Engel B., van Knapen F., de Jong M.C., Wagenaar J.A., Urlings H.A., 2003. Fermented liquid feed reduces susceptibility of broilers for Salmonella enteritidis. Poult. Sci. 82, 603-611, https://doi.org/10.1093/ps/82.4.603
Heres L., Urlings H.A.P., Wagenaar J.A., de Jong M.C.M., 2004. Transmission of Salmonella between broiler chickens fed with fermented liquid feed. Epidemiol. Infect. 132, 107-116, https://doi.org/10.1017/S0950268803001213

Hong K.-J., Lee C.-H., Kim S.W., 2004. Aspergillus oryzae GB-107 fermentation improves nutritional quality of food soybeans and feed soybean meals. J. Med. Food 7, 430-435, https:// doi.org/10.1089/jmf.2004.7.430

Ibrahim K.E., Al-Mutary M.G., Bakhiet A.O., Khan H.A., 2018. Histopathology of the liver, kidney, and spleen of mice exposed to gold nanoparticles. Molecules 23, 1848, https:// doi.org/10.3390/molecules23081848

Jazi V., Ashayerizadeh A., Toghyani M., Shabani A., Tellez G., Toghyani M., 2018. Fermented soybean meal exhibits probiotic properties when included in Japanese quail diet in replacement of soybean meal. Poult. Sci. 97, 2113-2122, https://doi.org/10.3382/ps/pey071

Kabir S.M.L., 2009. The role of probiotics in the poultry industry. Int. J. Mol. Sci. 10, 3531-3546, https://doi.org/10.3390/ ijms10083531

Kayode R.M.O., Sani A., Apata D.F., Joseph J.K., Annongu A.A., Kolawole O.M., Awe S., Obalowu M.A., Arekemase M.A., 2012. Performance and carcass characteristics of broiler chickens fed on fungal mixed-culture (Aspergillus niger and Penicillium chrysogenum) fermented mango kernel cake. Global Res. J. Microbiol. 2, 67-75

Kim S.K., Kim T.H., Lee S.K., Chang K.H., Cho S.J., Lee K.W., An B.K., 2016. The use of fermented soybean meals during early phase affects subsequent growth and physiological response in broiler chicks. Asian-Australas. J. Anim. Sci. 29, 1287-1293, https://doi.org/10.5713/ajas.15.0653

Li C.-Y., Lu J.-J., Wu C.-P., Lien T.-F., 2014. Effects of probiotics and bremelain fermented soybean meal replacing fish meal on growth performance, nutrient retention and carcass traits of broilers. Livest. Sci. 163, 94-101, https://doi.org/10.1016/j. livsci.2014.02.005

Mathivanan R., Selvaraj P., Nanjappan K., 2006. Feeding of fermented soybean meal on broiler performance. Int. J. Poult. Sci. 5 , 868-872, https://doi.org/10.3923/ijps.2006.868.872

Missotten J.A., Michiels J., Dierick N., Ovyn A., Akbarian A., De Smet S., 2013. Effect of fermented moist feed on performance, gut bacteria and gut histo-morphology in broilers. Br. Poult. Sci. 54, 627-634, https://doi.org/10.1080/00071668.2013.811718

Nava G.M., Attene-Ramos M.S., Gaskins H.R., Richards J.D., 2009. Molecular analysis of microbial community structure in the chicken ileum following organic acid supplementation. Vet. Microbiol. 137, 345-353, https://doi.org/10.1016/j. vetmic.2009.01.037

Nie C., Zhang W., Ge W., Wang Y., Liu Y., Liu J., 2015. Effects of fermented cottonseed meal on the growth performance, apparent digestibility, carcass traits, and meat composition in yellow-feathered broilers. Turk. J. Vet. Anim. Sci. 39, 350-356, https://doi.org/10.3906/vet-1410-65

PN-ISO 4832, 2007. Horizontal method for determining the number of coliforms - Plate method (in Polish)

PN-EN ISO 7218, 2008. Food and feed microbiology - General requirements and principles of microbiological tests (in Polish)

Savvidou S.E., Beal J.D., Brooks P.H., La Ragione R.M., 2009. Liquid feed fermented with Lactobacillus salivarius_reduces susceptibility of broiler chickens to Salmonella enterica typhimurium Sal 1344 nalr. Proc. Br. Soc. Anim. Sci. 2009, 201, https://doi.org/10.1017/S1752756200030404 
Seifi K., Karimi Torshizi M.A., Rahimi S., Kazemifard M., 2017. Efficiency of early, single-dose probiotic administration methods on performance, small intestinal morphology, blood biochemistry, and immune response of Japanese quail. Poult. Sci. 96, 2151-2158, https://doi.org/10.3382/ps/pew446

Seo S.-H., Cho S.-J., 2016. Changes in allergenic and antinutritional protein profiles of soybean meal during solid-state fermentation with Bacillus subtilis. LWT - Food Sci. Technol. 70, 208-212, https://doi.org/10.1016/j.lwt.2016.02.035

Siwicki A.K., Anderson D.P., 1993. Nonspecific defense mechanisms assay in fish. II. Potential killing activity of neutrophils and macrophages, lysozyme activity in serum and organs, and total immunoglobulin (lg) level in serum. In: A.K. Siwicki, D.P. Anderson, J. Waluga. Fish Diseases Diagnosis and Prevention Methods. The Stanisław Sakowicz Inland Fisheries Institute. Olsztyn (Poland), pp. 105-111

Smulikowska S., Rutkowski A., 2005. Nutrient Requirements of Poultry. Feeding Recommendations and Nutritive Value of Feed. $4^{\text {th }}$ Edition (in Polish). The Kielanowski Institute of Animal Physiology and Nutrition of the Polish Academy of Sciences, Jabłonna (Poland)

Sugiharto S., Ranjitkar S., 2019. Recent advances in fermented feeds towards improved broiler chicken performance, gastrointestinal tract microecology and immune responses: A review. Anim. Nutr. 5, 1-10, https://doi.org/10.1016/j.aninu.2018.11.001
Sun H., Tang J.-w., Yao X.-h., Wu Y.-f., Wang X., Feng J., 2013. Effects of dietary inclusion of fermented cottonseed meal on growth, cecal microbial population, small intestinal morphology, and digestive enzyme activity of broilers. Trop. Anim. Health Prod. 45, 987-993, https://doi.org/10.1007/s11250-012-0322-y

Sunderman F.W. Jr., Nomoto S., 1970. Measurement of human serum ceruloplasmin by its $\mathrm{p}$-phenylenediamine oxidase activity. Clin. Chem. 16, 903-910

Teng D., Gao M., Yang Y., Liu B., Tian Z., Wang J., 2012. Biomodification of soybean meal with Bacillus subtilis or Aspergillus oryzae. Biocatal. Agric. Biotechnol. 1, 32-38, https://doi.org/10.1016/j.bcab.2011.08.005

Wang L.C., Wen C., Jiang Z.Y., Zhou Y.M., 2012. Evaluation of the partial replacement of high-protein feedstuff with fermented soybean meal in broiler diets. J. Appl. Poult. Res. 21, 849-855, https://doi.org/10.3382/japr.2012-00563

Yuan L., Chang J., Yin Q., Lu M., Di Y., Wang P., Wang Z., Wang E., Lu F., 2017. Fermented soybean meal improves the growth performance, nutrient digestibility, and microbial flora in piglets. Anim. Nutr. 3, 19-24, https://doi.org/10.1016/j. aninu.2016.11.003

Zhang X-j., Lou H., Li J.-I., Xie D.-x., Xu J., Huo C.-m., Cui Y.-s., 2007. A study on benefit of feeding hy-line white egg with fermented feed. Southwest China J. Agric. Sci. 2007, 529-533 